\title{
TEN-YEAR FIELD STUDY OF WOOD PLASTIC COMPOSITES IN SANTIAGO, CHILE: BIOLOGICAL, MECHANICAL AND PHYSICAL PROPERTY PERFORMANCE
}

\author{
Douglas J. Gardner ${ }^{1, \triangleq}$, Alejandro Bozo ${ }^{2}$
}

\begin{abstract}
Outdoor durability of wood plastic composites is a major focus of research and development efforts toward development of more robust building materials. Exterior exposure of wood plastic composites can result in weathering, moisture absorption, fungal and termite attack to various levels of severity depending on the composite formulation. Long-term ( $>6$ years) field exposure studies of wood plastic composites are lacking in the scientific literature. It is the overall goal of this paper to report on a ten-year field study of wood plastic composites performed in Santiago, Chile. The wood plastic composite formulations were comprised of polypropylene, wood flour, and various additives. Qualitative measurements were made on the stakes each year including the determination of decay and termite ratings on a scale of 1 to 10 as specified in American Wood Preservers' Association Standards. Surface weathering or discoloration, surface fungi colonization, presence of mold, and/or lichen was noted. The amount of dimensional change (swelling) of the samples in ground contact was determined. Determination of flexural properties of the control and 10-year exposed wood plastic composite stakes were conducted. All the wood plastic composite stake formulations maintained excellent performance ratings after the 10 -year field exposure with ratings of 10 for decay and 10 for termites. The wood plastic composites stakes experienced swelling in contact with the soil with the majority of swelling occurring during the first year of exposure. Although the wood plastic composite stakes did well regarding decay and termite performance, the portion of the stakes exposed above ground exhibited various amounts of weathering, surface fungal colonization, and mold and mildew depending on the formulation. Flexural properties of the wood plastic composite stakes decreased or were maintained for the 10-year exposure depending on the composite formulation.
\end{abstract}

Keywords: Decay, flexural properties, polypropylene, termites, swelling.

\section{INTRODUCTION}

Thermoplastic wood plastic composites (WPCs) have found use in a myriad of building material applications including decking and railings, siding, doors and windows, roof shingles, etc. (Gardner et al. 2015). Outdoor durability of wood plastic composites (WPCs) has been a major focus of research and development effort over the past several decades (Klyosov 2007, Stark and Gardner 2008, Fabiyi and McDonald 2010, Tascioglu et al. 2013). Exterior exposure of WPCs results in ultraviolet light degradation and absorption of moisture to various amounts of severity depending on the composite formulation, i.e. wood content, polymer type and content as well as the presence of processing additives like lubricants, coupling agents, colorants, biocides, among others. (Butylina et al. 2012, 
Gnatowski 2005). Fungal decay occurs in WPCs exposed to severe environmental conditions such as is typical of a tropical environment like Hawaii (Ibach et al. 2016). Termite attack of WPCs has also been shown to occur in laboratory studies (Xu et al. 2015). Subterranean termites (Reticulitermes flavipes) (Isoptera: Rhinotermitidae) are found in Chile, mainly in the metropolitan regions of Santiago and Valparaiso. Termites are considered an urban plague that attacks all type of woods and wood-based materials. Subterranean termites have been identified in approximately 80 focus areas extending over most neighborhoods of Santiago. These census findings have demonstrated the aggressiveness and extent of termite attack. Thus, WPCs have the potential to resist termite attack. WPC materials can be placed in soil contact either as structural members or building components. WPC materials may have the potential to limit termite ingress into buildings.

Long-term ( $>6$ years) field exposure studies of WPCs are not prevalent in the scientific literature (Morrell et al. 2006, Schauwecker et al. 2006, Ibach et al. 2013) and may be attributable to the availability of sustained grant funding over a longer time period. Indeed the study being reported here started out as a 3 year project looking at termite resistance of WPCs, but was expanded to ten years. It is the overall goal of this paper to report on a ten-year field study of wood plastic composites performed at the Faculty of Forestry Sciences and Nature Conservation of University of Chile field site outside Santiago, Chile between October 19, 2005 and August 8, 2015.

\section{METHODS AND MATERIALS}

The WPC stake formulation recipes are shown in Table 1. The WPC stakes examined include a formulation developed the United States Coastguard (USCG) waterfront facilities and several experimental WPC formulations. The wood flour (40 mesh pine) was obtained from American Wood Fiber, Inc. (Schofield, WI). The polypropylene (PP) used to manufacture the stakes was either virgin H05A-00 PP homopolymer from Ineos (USCG and 072105-C) or recycled PP from recycled lobster trap float rope (FR) material (green, white and brown) (Smith 2005). The processing aid (lubricant) TPW 113 was obtained from Struktol ${ }^{\circledR}$ (Stow, Ohio).Colorant (grey pigment with UV inhibitor) was obtained from Clariant (Lewiston, Maine). The maleic anhydride PP Polybond 3200 was obtained from Chemtura (Crompton).

The wood plastic composite lumber to create the stakes was manufactured on a Davis-Standard Woodtruder ${ }^{\mathrm{TM}}$ using either a $18,75 \mathrm{~mm}$ x $137,5 \mathrm{~mm}$ or a $31,25 \times 137,5 \mathrm{~mm}$ deck board lumber profile die. The WPC lumber was machined to produce the $18,75 \mathrm{~mm} \times 18,75 \mathrm{~mm} \times 450 \mathrm{~mm}$ field stakes. Fifteen stakes were prepared for each WPC formulation for the field exposure study. Control stakes were also made for flexural testing.

Table 1. Wood plastic composite stake formulations evaluated during 10-year field exposure in Santiago, Chile.

\begin{tabular}{|l|l|l|l|l|l|}
\hline Sample & \multicolumn{1}{|c|}{$\begin{array}{c}\text { Wood } \\
\text { (Wt.\%) }\end{array}$} & \multicolumn{1}{|c|}{$\begin{array}{c}\text { Polypropylene } \\
\text { (Wt.\%) }\end{array}$} & $\begin{array}{c}\text { Lubricant } \\
\text { (Wt.\%) }\end{array}$ & $\begin{array}{c}\text { Colorant } \\
\text { (Wt.\%) }\end{array}$ & \multicolumn{1}{|c|}{$\begin{array}{c}\text { MAPP } \\
\text { (Wt.\%) }\end{array}$} \\
\hline FR Green & 52 & 42 & 4 & 1 & 1 \\
FR White & 52 & 42 & 4 & 1 & 1 \\
FR Brown & 52 & 43 & 4 & 0 & 1 \\
USCG & 49,75 & 40,25 & 4,3 & 3,4 & 2,3 \\
072105-C & 49 & 44 & 4 & 0 & 3 \\
\hline
\end{tabular}

Radiata pine (Pinus radiata D. Don) wood stakes (10) and chromated copper arsenate (CCA) pressure-treated radiata pine stakes (10) served as controls for the field exposure experiments. 


\section{Description of WPC Stake Field Exposure Site}

The site for the WPC stake field exposure measurements was located at the University of Chile near the Department of Wood Engineering and Sustainable Biomaterials facility in Santiago, Chile (Figure 1). The climate in Santiago is considered Mediterranean i.e. warm temperate with a long dry season. The average yearly rainfall measured during the 10 -year field exposure is listed in Table 2 .

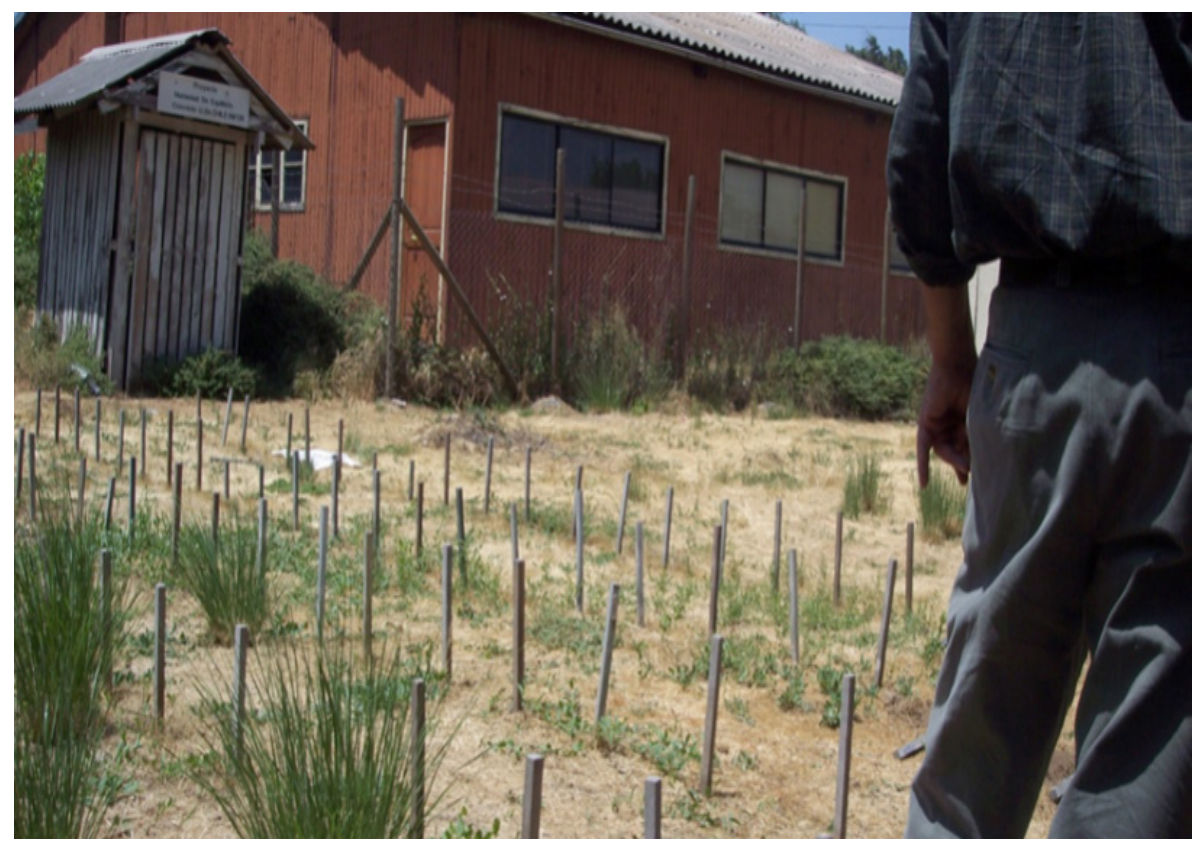

Figure 1. WPC stake test field site (Year 3) at the University of Chile in Santiago, Chile.

The averageyearly rainfall(precipitation) in SantiagoatQuinta Normalmeteorological station is 312,5 mmand theyearly averagetemperature is $15^{\circ} \mathrm{C}$.Asseen in Table 2 the annual precipitation was quite variable over the 10-year field study and this can be attributed in part to the El Niño and La Niña weather phenomena.

Table 2.Yearly rainfall $(\mathrm{mm})$ measure in Santiago, Chile over the 10-year WPC stake field test.

\begin{tabular}{|c|c|c|c|c|c|c|c|c|c|c|c|}
\hline Year & 2005 & 2006 & 2007 & 2008 & 2009 & 2010 & 2011 & 2012 & 2013 & 2014 & $2015^{*}$ \\
\hline $\begin{array}{c}\text { Rainfall } \\
(\mathrm{mm})\end{array}$ & 353,8 & 335,6 & 168,4 & 350,8 & 276,8 & 259,5 & 147,5 & 215,8 & 134,3 & 131,6 & 154,1 \\
\hline
\end{tabular}

*Until the end of August; no WPC stake readings were made in Year 5 (2010).

\section{Stake Measurements}

Qualitative measurements were made on the stakes each year starting in 2006 including decay and termite ratings on a scale of 1 to 10 as specified in American Wood Protection Association (AWPA) Standards (1991) E7-90. Surface weathering or discoloration, surface fungi colonization, presence of mold, and/or lichen was noted and photographs of the stakes were taken for documentation purposes. As the stakes were removed from the ground and inspected each year, additional measurements were made including measuring the width and thickness of the samples (ground contact end) to determine amount of dimensional changes of the sampled in ground contact (Figure 2). 


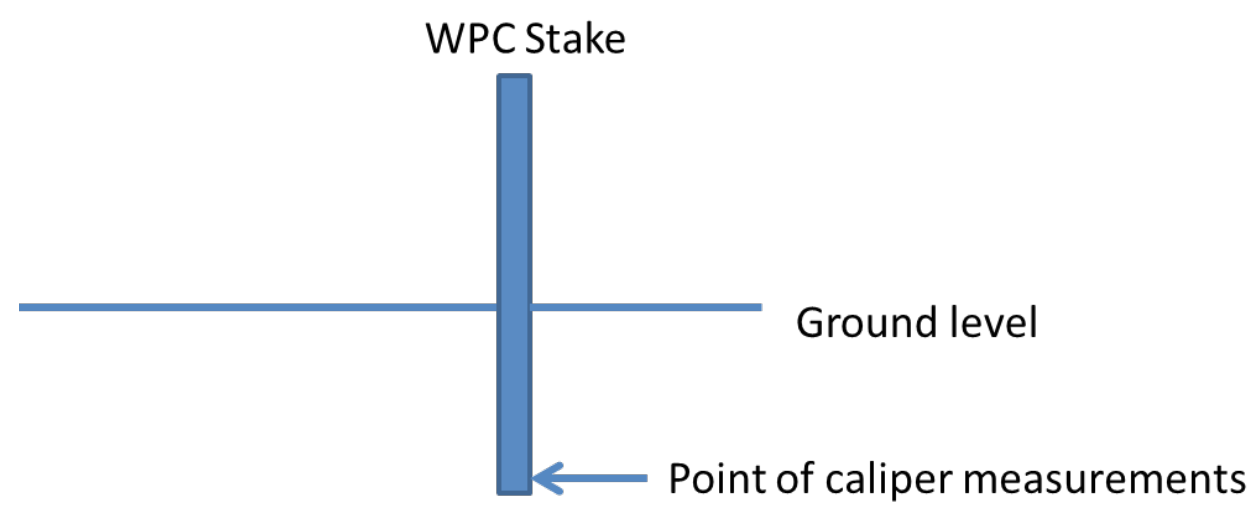

Figure 2. Location on the WPC stakes where dimensional measurements were made on the samples during each yearly inspection. Flexural Testing

Flexural testing of control and 10-year exposed WPC stakes was conducted in accordance with ASTM D 6109. The stake samples were cleaned and conditioned in the laboratory at $23{ }^{\circ} \mathrm{C}$ and $50 \%$ relative humidity for several months. Each of the 15 replicates per formulation were tested using an Instron 22-kip actuator fitted with a four point test fixture at a span of $300 \mathrm{~mm}$ and a rate of $9 \mathrm{~mm} / \mathrm{min}$.

\section{Statistical Analysis}

Qualitative decay and termite ratings were tabulated and descriptive statistics were determined. The modulus of rupture and modulus of elasticity data were compared using an analysis of variance followed by a Tukey-Kramer Honestly Significant Differences (HSD) using JMP software (2008).

\section{RESULTS AND DISCUSSION}

\section{Decay and Termite Ratings}

The final (year-10) decay and termite stake ratings are listed in Table 3. All the WPC stake formulations maintained excellent performance ratings after the 10-year field exposure with ratings of 10 for decay and 10 for termites. The CCA pressure treated radiata pine also performed well with a decay rating of 9,3 and termite rating of 9,7 . However, as expected the untreated control radiata pine stakes did not perform well with and average decay rating of 5,6 and termite rating of 6,9. A few of the untreated control stakes failed after 6 years of exposure. There was only limited evidence of termite attack on the untreated control stakes as shown in Figure 3. The stake shown in Figure 3 was attacked by termites between year 2 and year 3, but no further termite damage was detected in subsequent years. One possible explanation for the limited termite attack and variable decay results for the untreated controls might be attributed to the below average rainfall between 2009 and 2015. Indeed, the yearly rainfall for 2011, 2013-2015 was 50\% below the yearly average rainfall of 312,5 mm. Dry conditions 
are known to suppress termite and decay attack (Ross 2010).

Table 3.WPC stake decay and termite ratings after 10-year field exposure in Santiago, Chile.

\begin{tabular}{|l|ll|}
\hline WPC Stake Sample Formulation & Decay Rating & Termite Rating \\
\hline Green recycled polypropylene float rope & 10 & 10 \\
Brown recycled polypropylene float rope & 10 & 10 \\
White recycled polypropylene float rope & 10 & 10 \\
Grey U.S. Coast Guard (USCG) polypropylene formulation & 10 & 10 \\
Crompton MAPP PP formulation -no colorant & 10 & 10 \\
Untreated radiata pine control stakes & 5,6 & 6,9 \\
CCA pressure treated radiata pine control stakes & 9,3 & 9,7 \\
\hline
\end{tabular}

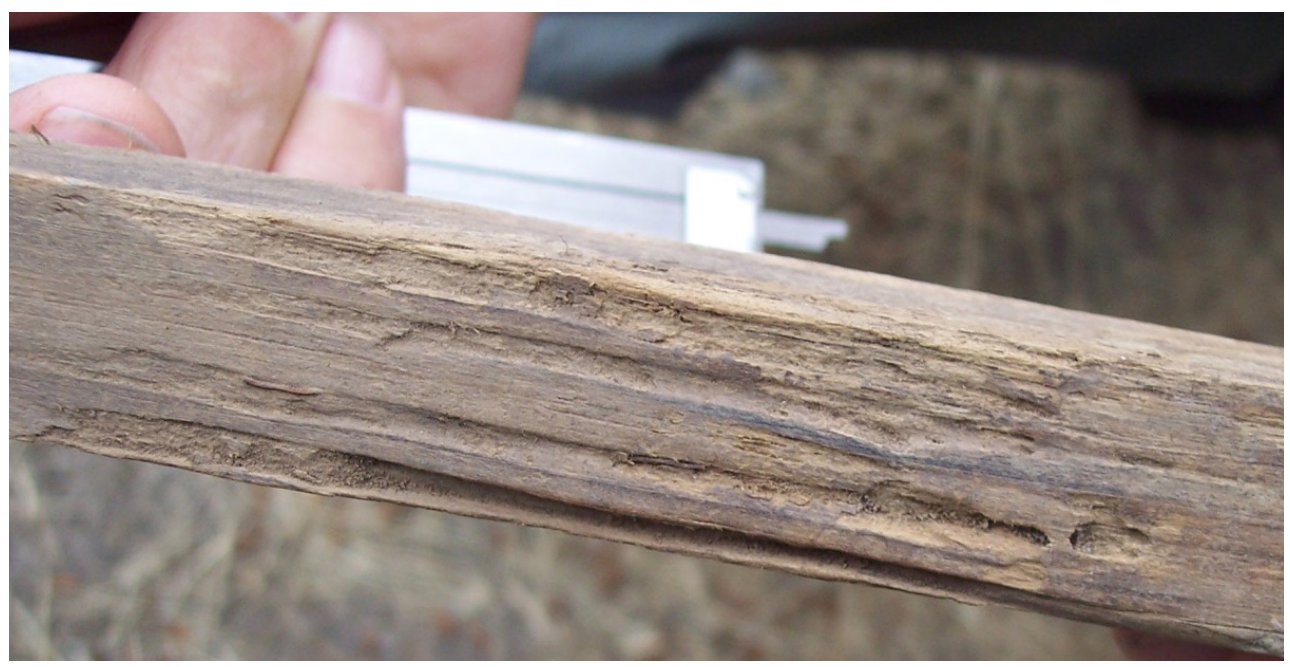

Figure 3. Termite attack on untreated radiata pine wood control stake detected during year-3 inspection trip.

\section{Surface Weathering and Biological Colonization}

Although the WPC stakes did well regarding decay and termite performance, the portion of the stakes exposed above ground in the field exposure provided interesting performance behavior related to weathering, surface fungal colonization, and mold and mildew. The stakes with no added colorant in the formulation faded to a light grey within 2 to 3 years of exposure and this behavior was in line with similar research on both low and high density polyethylene WPCs reported in the literature (Schauwecker et al. 2006, Fabiyi et al. 2008) Stakes with no colorant added also experience "chalking" of the surface and this behavior is in line with the results on artificially weathered PP WPCs reported by Fabiyi and McDonald 2014. All of the stakes supported the colonization of mold and mildew to some extent. A few stakes also supported the growth of lichen. The USCG WPC formulation performed best in terms of limited weathering and limited biological colonization. Figure 4 shows examples of WPC stake surface biological colonization after 10-year field exposure in Santiago, Chile. The spotty surface fungal colonization on some stakes suggests the beginning of superficial white rot attack. Since this study began in 2005 , it is interesting to note that most commercial producers of WPC decking have transitioned to co-extruded products that have surface layers that reduce the issues of weathering, and surface biological colonization (Gardner et al. 2015). 


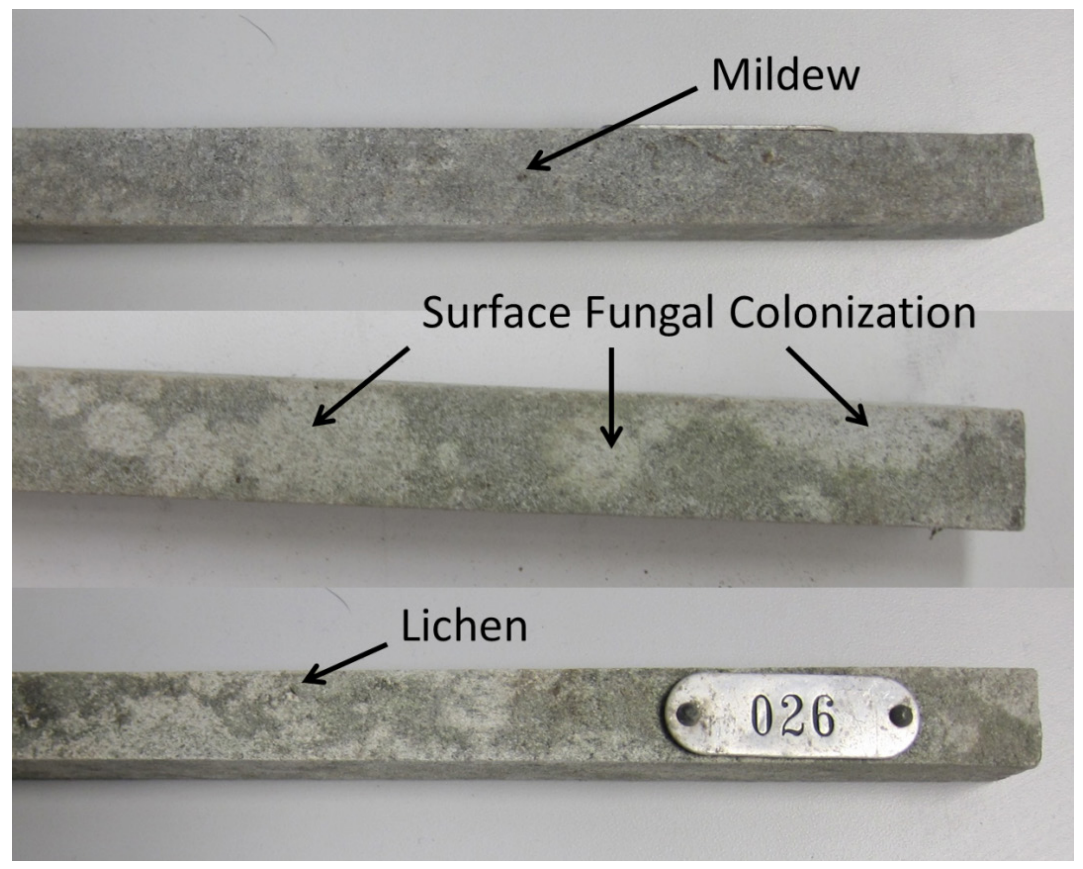

Figure 4. Examples of WPC stake surface biological colonization after 10-year field exposure in Santiago, Chile.

\section{Dimensional change data for 10 years}

The dimensional change (percent swelling) data for selected WPC stakes and wood controls over the 10-year field study exposure are shown in Figure 5. For the WPC stakes, the most swelling occurred during the first year of soil exposure. This result is consistent with an earlier study examining the water absorption of WPCs in exterior exposure (Gnatowski 2005). Swelling for year-1 ranged from 3,3\% for the USCG formulation to 5,2 \% for the brown float rope formulation. Year 9 saw the largest increase in dimensions for the WPC stakes ranging from 5,9\% for the white float rope formulation to $6,7 \%$ for the green float rope formulation. The untreated and pressure treated wood samples swelled to a much smaller amount compared to the WPC stakes. In year-1 the wood and PT wood swelled 2,0\% and $0,8 \%$, respectively and $4,8 \%$ and $0,6 \%$ respectively in year 9 . Prior to making the dimensional measurements in year-10, the field site must have been quite dry since both the WPC stakes and wood samples shrank considerably. The WPC stakes ranged from $0,8 \%$ to $1,6 \%$ swelling for the USGC and white float rope, respectively and the wood and PT wood shrank to 5,6 \% and 4,1\%, respectively. The wood stakes responded more rapidly to changes in soil moisture content and percent swelling tended to follow the trend of the changes in annual precipitation over the life of the field exposure (Table 2). 


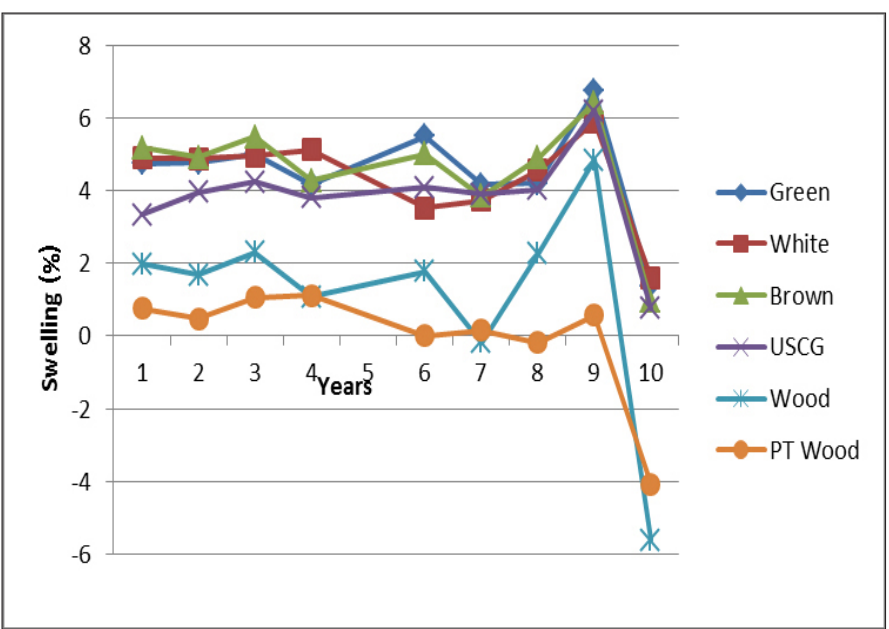

Figure 5. Percent swelling data (y axis) for WPC stakes and wood controls over the 10-year ( $\mathrm{x}$ axis) field study exposure.

\section{Flexural data}

The flexural properties of the WPC stakes are shown in Figure 6 and Figure 7. It was expected that with the absorption of moisture during the field exposure that the flexural properties of the WPC stakes would be reduced (Stark 2001). The flexural strength of the brown and green float rope control stakes was significantly stronger than weathered stakes. However, the USCG formulation exhibited no significant difference in flexural strength between the control and weathered stakes and this might be attributed to the greater amount of coupling agent $2,3 \%$ versus $1 \%$ in the formulation as well as the greater amount of colorant that would reduce weathering related degradation of the USCG stakes. Interestingly, the weathered white float rope stakes were stronger than control stakes and this might be attributed to the type of polypropylene used in manufacturing the float rope.

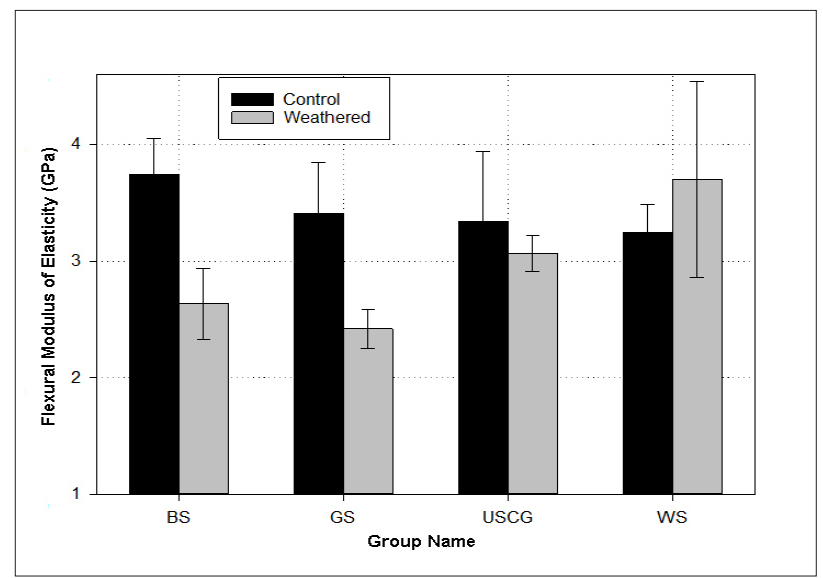

Figure 6. Flexural strength of weathered and control WPC stakes.

The flexural stiffness of the brown and green float rope control stakes was significantly greater than the weathered stakes while the stiffness of the USCG and white float rope stakes was not significantly different between the weathered and control samples. Again, these results are attributable to the composite formulation, where the USCG stakes included a greater amount of coupling agent and colorant that protected the flexural properties of the sample, and this is supported by other field studies (Ibach et al. 2007). These results show the importance of creating a WPC composite formulation that can maintain material properties (durability) for the long-term. 


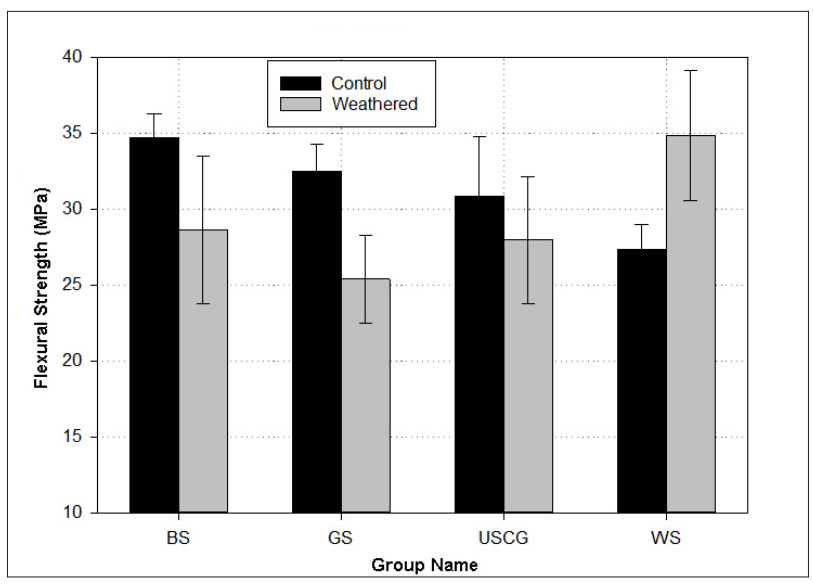

Figure 7. Flexural stiffness of weathered and control WPC stakes.

\section{CONCLUSIONS}

This paper successfully reported on a ten-year field study of WPCs performed in Santiago, Chile.

The WPC formulations were comprised of polypropylene, wood flour, and various additives. All the WPC stake formulations maintained excellent performance ratings after the 10-year field exposure with ratings of 10 for decay and 10 for termites. The WPC stakes experienced swelling in contact with the soil with the majority of swelling occurring during the first year of exposure. Although the WPC stakes did well regarding decay and termite performance, the portion of the stakes exposed above ground exhibited various amounts of weathering, surface fungal colonization, and mold and mildew depending on the formulation. Flexural properties of the WPC stakes decreased or were maintained over the 10-year exposure period depending on the composite formulation. The results of this study suggest that PP-based WPCs will perform well against termites and decay fungi in soil contact building construction applications in the Santiago region of Chile.

\section{ACKNOWLEDGEMENTS}

Funding for this study came in part from the Office of Naval Research Pan American Collaboration on Wood Composites, Long Range Navy and Marine Corp. Science and Technology Program BAA 04-001Task 4 Termite Resistant Wood Plastic Composites for Building Construction, and the Maine Agricultural and Forest Experiment Station (MAFES) projects ME09615-08MS and the National Science Foundation Research Experience for Undergraduates Project EEC-1063007 Explore It! Building the Next Generation of Sustainable Forest Bioproduct Researchers. Thanks to the University of Chile for providing the test site for the WPC field study. The authors express great appreciation for the assistance with the yearly field stake monitoring and measurements from a variety of willing helpers including Victor Gaete, Aldo Cisternas, Tomas Karsulovic, Stephen Shaler, Jon Hill, Russell Edgar, David Neivandt, and Camillo Gaete. Thanks to Mustafa Zor for help with flexural testing of the weathered WPC stakes and Alper Kiziltas for running the analysis of variance on the flexural testing data. 


\section{REFERENCES}

ASTM. 2005. Standard Test Methods for Flexural Properties of Unreinforced and Reinforced Plastic Lumber and Related Products. ASTM D6109-05.

AWPA. 1991. Standard method of testing wood preservatives by field tests with stakes. AWPA E7-90, Woodstock, Md.

Butylina, S.; Hyvarinen, M; Karki, T. 2012. A study of surface changes of wood-polypropylene composites as the result of exterior weathering. Polymer Degradation and Stability 97(3):337-345.

Fabiyi, J.S.; McDonald, A.G. 2010. Effect of wood species on property and weathering performance of wood plastic composites. Composites Part A: Applied Science and Manufacturing 41(10):1434-1440.

Fabiyi, J.S.; McDonald, A.G.; Wolcott, M. P.; Griffiths, P. R. 2008. Wood plastic composites weathering: Visual appearance and chemical changes. Polymer Degradation and Stability 93(8):14051414.

Fabiyi, J.S.; McDonald, A.G. 2014. Degradation of polypropylene in naturally and artificially weathered plastic matrix composites. Maderas. Ciencia y Tecnología 16(3):275-290.

Gardner, D.J.; Han, Y; Wang, L. 2015. Curr. Forestry Report: 139. doi:10.1007/s40725-0150016-6.

Gnatowski, M. 2005. Water absorption by wood plastic composites in exterior exposure.In Proceedings of the $8^{\text {th }}$ International Conference on Woodfiber-Plastic Composites (and other natural fibers) (pp. 23-25).

Ibach, R.; Sun, G.; Gnatowski, M.; Glaeser, J.; Leung, M.; Haigth, J. 2016. Exterior Decay of Wood-Plastic Composite Boards: Characterization and Magnetic Resonance Imaging. Forest Products Journal 66(1):4-17.

Ibach, R.E.; Gnatowski, M.; Sun, G. 2013. Field and laboratory decay evaluations of woodplastic composites. Forest Products Journal 63(3):76-87.

Ibach, R.E.; Clemons, C.M.; Schumann, R.L. 2007. Wood-plastic composites with reduced moisture: Effects of chemical modification on durability in the laboratory and field. In Proceedings of the $9^{\text {th }}$ International Conference on Wood \& BioFiber Plastic Composites, Forest Products Society pp. 259-266.

JMP. 2008. Statistical Discovery Software, Version 8. SAS Institute, Inc., Cary, NC.

Klyosov, A.A. 2007. Wood-plastic composites. John Wiley \& Sons.

Morrell, J.J.; Stark, N.M.; Pendleton, D.E; McDonald, A.G. 2006. Durability of wood-plastic composites. Wood Design Focus 16(3):7-10.

Ross, R.J. 2010. Wood handbook : wood as an engineering material. USDA Forest Service, Forest Products Laboratory, General Technical Report FPL- GTR-190, 509 p.

Schauwecker, C.; Morrell, J. J. ; McDonald, A. G. ;Fabiyi, J. S. 2006. Degradation of a woodplastic composite exposed under tropical conditions. Forest Products Journal 56(11/12):123-129.

Smith, T. 2005. Article on the potential for recycling float rope used by lobstermen. [Available] Mainebiz 3219. 24 pp. <http://digitalcommons.portlandlibrary.com/news_mainebiz/3219/>

Stark, N. 2001. Influence of moisture absorption on mechanical properties of wood flourpolypropylene composites. Journal of Thermoplastic Composite Materials 14(5):421-432.

Stark, N.M.; Gardner, D.J. 2008. Outdoor durability of wood-polymer composites (pp. 142- 
165). Woodhead Publishing, Philadelphia.

Tascioglu, C.; Yoshimura, T; Tsunoda, K. 2013. Biological performance of wood-plastic composites containing zinc borate: Laboratory and 3-year field test results. Composites Part B: Engineering 51:185-190.

Xu, K.; Feng, J.; Zhong, T.; Zheng, Z.; Chen, T. 2015. Effects of volatile chemical components of wood species on mould growth susceptibility and termite attack resistance of wood plastic composites. International Biodeterioration \& Biodegradation 100:106-115. 